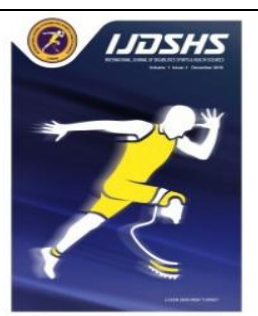

\title{
The Effect of Exercise Training for Refugee Wheelchair Users
}

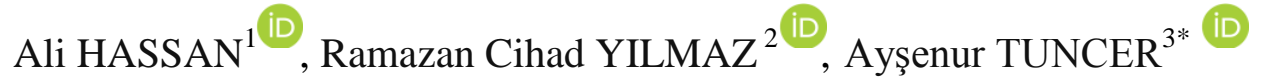

${ }^{1}$ Academic Physical Therapy Center Hatay-Reyhanlı, Turkey

${ }^{2}$ Iğdır University, Faculty of Health Sciences, Department of Physiotherapy and Rehabilitation, Iğdır, Turkey

${ }^{* 3}$ Hasan Kalyoncu University Faculty of Health Sciences Department of Physiotherapy and Rehabilitation, Gaziantep, Turkey

*Corresponding author: aysenur.tuncer@hku.edu.tr

\begin{abstract}
Purpose: The aim of this study was to investigate the effect on head and shoulder posture, pain, neck disability, functional capacity, fatigue, and quality of life of exercise training applied to the upper extremity, scapular, and trunk muscles of refugees using a wheelchair because of spinal cord injury sustained in the Syrian War. Methods: The study included 24 refugees aged 20-35 years who were using a wheelchair. The subject were randomly separated into 2 groups as the control group (n:12), who recieved upper extremity strengthening exercises only, and the study group (n:12), who recieved additional scapular and trunk strengthening exercises. The exercise program was implemented 3 times a week for 4 weeks. Head and shoulder posture angular values were measured with a goniometer. Evaluations were made usingthe Wheelchair User's Shoulder Pain Index (WUSPI), Neck Disability Index (NDI), Fatique Severity Scale (FSS), Functional Independence Measure (FIM), and the World Health Organization Quality of Life short form (WHO-QoL-Bref). Results: Before treatment, the measurements of the groups were homogenous ( $\mathrm{p}>0.05)$. In the post-treatment evaluations, the shoulder pain, neck disability, and fatigue severity values were significantly lower, and the functional independence and quality of life scores showed a significant improvement in the study group after the training $(\mathrm{p}<0.05)$. Conclusion: The study results demonstrated that the addition of scapular and trunk strengthening exercise to upper extremity exercises in the rehabilitation of wheelchair users is more effective in improving head and shoulder posture, neck disability, fatigue severity, functional independence, and quality of life.
\end{abstract}

\section{Keywords}

Refugee, Wheelchair, Exercise, Quality of life

\section{INTRODUCTION}

The disabilities seen in refugees from war at all ages and in both genders include hearing, sight, and physical problems, and speech disorders. For victims of the Syrian War who are now confined to a wheelchair because of spinal cord injury and living as refugees in Turkey, when the problems of migration and refugee life are added, the frequency and severity of the difficulties encountered by wheelchair users are increased.

Spinal cord injuries (SCI) with various clinical characteristics have a pathological process with a negative effect on social, psychological, personal, and economic life. Many complications may develop following SCI, primarily several musculoskeletal system problems associated with wheelchair use characterized mainly by neck and shoulder pain and problems (Tatlı et al., 2005). It has been reported that $68 \%$ of wheelchair users experience problems in the shoulders and surrounding joints, and pain and function loss is seen in the neck, elbow and wrist, as other joints close to the shoulder (Curtis et al., 1999; Nichols et al., 1979; Curtis et al., 1995). Excessive loading and repeated activities extending the head as a result of wheelchair use have been reported to 
cause often decreased intra-articular circulation in the upper extremity joints, which leads to pain (Curtis et al., 1999). This decrease in circulation causes pain and function loss and long-term joint destruction because of joint fluid and intraarticular feeding (Subbarao et al., 1995).

In addition to the above-mentioned joint disorders, postural problems often develop in SCI patients who are wheelchair-dependent. Previous studies have shown postural problems such as anterior pelvic tilt, head anterior tilt, neck and shoulder protraction, and kyphotic posture in longterm wheelchair users because of SCI, and it has been shown that these postural deviations lay the ground for several diseases and dysfunctions (Nichols et al., 1979; Rose et al., 1988; Sakai et al., 2020).

When it is considered that the upper extremity joints are in conditions of continuous overuse in patients who have to use a wheelchair, these joints' health is critical to provide a good quality of life for these types of wheelchairdependent individuals (Sakai et al., 2020). A decrease in physical adaptation is a serious barrier to maintaining functionality and may cause loss of independence for the wheelchair user (Tolerico et al., 2007). Therefore, to increase the exercise capacity of these individuals, their general health and quality of life should be improved (Kirby et al., 2020).

The importance of planned, structured, and repeated exercises to develop and maintain the body vitality has been stated in studies showing that individuals with SCI are inactive (Buchholz et al., 2003). With exercise interventions, SCI patients can become more physically active, and this has been shown to be an effective means of reducing preventable diseases (Kressler et al., 2014).

The importance of performing regular physical activity following spinal cord injury has been emphasized, especially the importance of exercise to encourage and maintain functional independence (Hicks et al., 2003). The focus has been on exercise programs to strengthen the upper extremity muscles in terms of reducing deterioration of the musculoskeletal system and reducing fatigue in this patient group. There is general evidence that exercises performed by wheelchair users are effective therapeutic approaches in providing trunk control, increasing functional capacity, and increasing resistance to fatigue.

There are studies in the literature that have used ergonomic changes to increase the quality of life of long-term wheelchair users (Curtis et al., 1999; Hicks et al., 2003; Harvey, 2016). However, there is no study that has investigated whether or not the above-mentioned problems can be eliminated with exercise approaches focussed on pain, fatigue, and sleep quality with the strengthening of scapula, trunk, and upper extremity muscles. Especially in the studies conducted on refugees, there has been seen to be more focus on social content evaluation. In addition to basic health requirements, to accelerate the stages of adaptation to community life and increase the quality of life, individuals living temporarily in refugee camps have been referred for therapeutic exercises to increase activity and socialization.

The aim of this study was to investigate the effect on head and shoulder posture, shoulder pain, neck disability, functional capacity, fatigue, and quality of life of exercises applied to the upper extremity, scapular, and trunk muscles of patients living in a refugee camp and using a wheelchair because of spinal cord injury sustained in the Syrian War. The study hypothesis was that the exercises applied to the scapular and trunk muscles together with the upper extremity would have a greater effect than an exercise program of upper extremity exercises only on correcting head and shoulder posture, increasing functional capacity, and decreasing fatigue levels.

\section{MATERIAL AND METHODS}

The study was conducted on individuals using a wheelchair because of SCI sustained in the Syrian War and living in a refugee camp. Approval for this randomized controlled trial was granted by the Human Research Ethics Committee of Hasan Kalyoncu University (date-decision no: 06/06/2018-2018/05). All study procedures conformed to the provisions of the World Medical Association Declaration of Helsinki. Written informed consent was obtained from all participants.

The aim of this study was to investigate the effect on head and shoulder posture, shoulder pain, functional capacity, fatigue, neck disability index, and quality of life of exercises applied to the upper 
extremity, scapular and trunk muscles of patients using a wheelchair because of spinal cord injury (SCI).

24 volunteers, between age 21-29, using wheelchair due to SCI, attending a special education and rehabilitation center in the province of Hatay, were included in the study. The individuals were divided into two groups according to the simple random method as the 1st control group $(\mathrm{n}=12)$ and the 2 nd study group ( $=12$ ). Only upper extremity strengthening exercises were applied to individuals in the control group, upper extremity strengthening exercises and scapular and trunk muscle strengthening exercises were applied to individuals in the study group

At the start of the study, the demographic information of all the subjects in both groups was recorded, then the Wheelchair User's Shoulder Pain Index (WUSPI), Neck Disability Index (NDI), Fatigue Severity Scale (FSS), Functional Independence Measure (FIM) and the World Health Organization Quality of Life short form (WHO-QoL-Bref) were applied. At the end of 12 training sessions completed in a 4-week period, all the evaluations and scales were applied again.

The appearance of the head and shoulder posture was photographed from the side with a digital camera (Canon 60D, Japan). Head and shoulder posture was measured using a digital goniometer with Adobe Acrobat software, with the camera at a distance of $1.5 \mathrm{~m}$ and adjusted to shoulder height at a fixed point without turning or bending (Ahmadi et al., 2016; Ruivo et al., 2017).

Head posture is defined as the craniovertebral angle. It is the angle formed by the intersection of a horizontal line along the spinous process of $\mathrm{C} 7$ and the line drawn towards the ear tragus. A craniovertebral angle of $\left\langle 48-50^{\circ}\right.$ is accepted as an anterior tilt of the head (Ahmadi et al., 2016) (Figure 1).

Shoulder posture is the angle formed by the intersection of the line drawn between the midpoint of the humerus and the spinous process of $\mathrm{C} 7$ and the horizontal line drawn along the midpoint of the humerus. A shoulder angle of $<52^{\circ}$ indicates shoulder protraction (Ruivo et al., 2017) (Figure1).

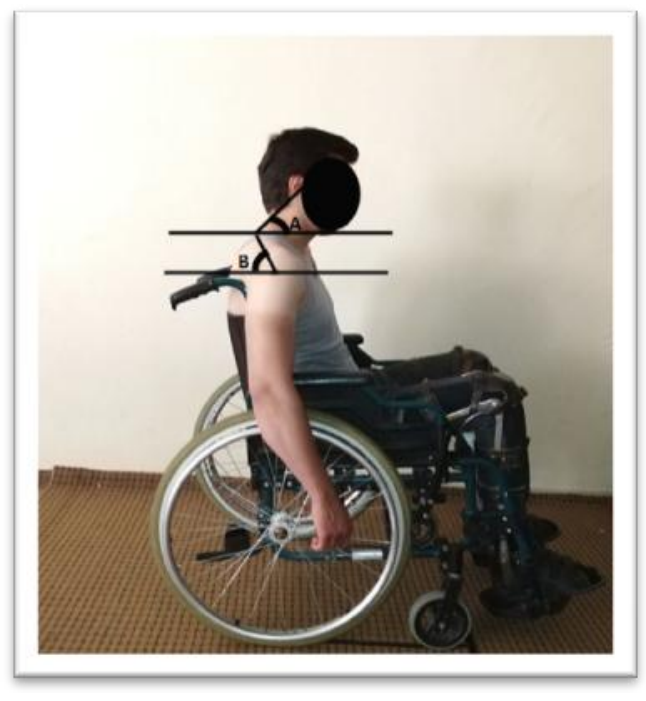

Figure 1. A: Head angle; B: Shoulder angle

Table A. Additional exercises for the study group

- With modified push-ups in the prone position on the bed, it was aimed to strengthen the trunk extension, scapular stabilization, serratus anterior part, and arm extensor muscles.

- In the sitting position, with the exercise of pushing a roller upwards on a wall, it was aimed to work the trunk extension and bilateral inferior trapezius muscles and with the action of moving the roller downwards to strengthen the trunk flexion the serratus anterior part, and the arm extensor muscles.

- Pulling the resistance band downwards bilaterally while in a sitting position works the serratus anterior part muscles and the muscles making flexion of the trunk.

- Using the resistance band in the sitting position with bilateral shoulders at $90^{\circ}$, by making a scapular retraction, the rhomboid muscles are strengthened.

- In a sitting position with the arms next to the trunk and the elbow in flexion, right and left shoulder internal rotation and external rotation exercises against the resistance of the band strengthened the scapular internal and external rotator muscles. 


\section{Shoulder Pain Index}

This scale was developed as the Wheelchair User's Shoulder Pain Index (WUSPI) to evaluate the severity of shoulder pain experienced during activities such as dressing, transfer, and propelling the wheelchair, and the quality of life of the patients (Curtis et al., 1999). The scale comprises 15 items in which shoulder pain severity during wheelchair use, transfers, personal care, and general activities is evaluated with a standard $10 \mathrm{~cm}$ Visual Analog Scale (VAS) where $0=$ no pain and $10=$ intolerable pain. The patient is instructed to mark the VAS to indicate the shoulder pain felt during the activities in the previous week. The total score is calculated from the total of the 15 item points, in the range of 0 150 , with 0 indicating no pain in any activity and 150 indicating the most severe level of pain in every activity. Validity and reliability studies of the WUSPI in Turkish were conducted by Yilmaz in 2017 (Y1lmaz, 2017).

\section{Neck Disability Index (NDI)}

This scale was developed by Vernon and Mior in 1991 to determine the level of disability of the neck (Vernon et al., 1991). The scale includes 10 different situations to evaluate the disability status of the neck. Validity and reliability studies of the NDI in Turkish were conducted by Aslan et al., in 2008 (Aslan et al., 2008).

\section{Fatigue Severity Scale (FSS)}

The FSS, which was developed in 1989, was applied to the individuals in the study to determine the levels of fatigue. Validity and reliability studies of the FSS in Turkish were conducted on MS patients by Armutlu et al. The scale consists of a total of 9 items scored with a 7-point Likert-type response, where 1 represents complete disagreement with the statement, and 7, complete agreement. The total score is calculated as the arithmetic mean of the total item scores. A score of $\geq 4$ generally indicates severe fatigue (Armutlu et al., 2007). The FSS was applied to the study subjects in the afternoon.

\section{Functional Independence Measure (FIM)}

The FIM, which was developed in 1993 (Hall et al., 1993), was used to determine the functional independence of the study subjects. Validity and reliability studies of the FIM in Turkish were conducted by Kucukdeveci et al., in
2001 (Kucukdeveci et al., 2001). The scale has 6 sub-dimensions which evaluate personal care, sphincter control, transfer, behavior when moving location, communication skills, and social perceptions. The sub-dimensions were evaluated by the researcher in accordance with specified criteria.

\section{World Health Organization Quality of Life - Short Form (WHO-QoL-Bref)}

This scale, developed in 1998, was used to evaluate the quality of life of the study participants. The scale comprises 26 items in 5 sub-dimensions of general health status, physical health status, psychological health status, social relationships, and support network (WHO-QoL Group, 1998). Validity and reliability studies of the WHO-QoL in Turkish were conducted by Eser et al., in 1999 (Eser et al., 1999).

\section{Intervention}

The control group subjects were applied with strengthening exercises for the upper extremities using resistance bands. With the subject sitting in the wheelchair, flexion and extension exercises were applied to the anterior, mid, and posterior deltoid, biceps and triceps, and the wrist. Under the supervision of a physiotherapist, a total of 4 weeks of exercise training was given 3 days a week and 3 sets for each muscle, with 10 repetitions, with 2-minute rest intervals.

The different colors of the resistance bands indicated different levels of resistance(http://www.therabandturkiye.com/theraband-renkleri/,2021). The color of the band used for each subject was determined by the muscle strength values and the weekly change in the muscle strength values. The bands were changed as necessary.

The subjects in the study group were given exercises directed at the muscles of the scapula and flexion and extension muscles of the trunk in addition to the control group exercises. The exercise training was given under the guidance of a physiotherapist as 10 repetitions and 3 sets for each muscle, with 2 minutes rest between the sets, 3 days a week for 4 weeks (Table A). 


\section{Statistical Analysis}

Data obtained in the study were analyzed statistically using IBM SPSS vn. 21.0 software (SPSS Inc, Chicago, IL, USA). As the data did not conform to a normal distribution, non-parametric tests were used in the analyses. In the comparisons of the mean values of two independent groups, the Mann-Whitney U test was used. The mean values within a group of the measurements taken before and after exercise training were evaluated using the Wilcoxon Signed-Rank test. In the determination of the differences between groups of categorical variables, the Chi-square test was applied. In all the data analyses, a value of $p<0.05$ was accepted as statistically significant.

\section{RESULTS}

The demographic data and some clinical characteristics of the classic exercise control group and the study group are shown in Table 1. A total of 24 males were examined, with a mean age of $24.83 \pm 0.88$ years in the control group and $24.58 \pm 0.73$ years in the study group $(\mathrm{p}>0.05)$. The groups were similar in respect of height, weight, educational level, smoking status, dominant side, and marital status ( $\mathrm{p}>0.05)$.

Table 1. Demographic data and clinical characteristics of the study subjects

\begin{tabular}{|c|c|c|c|c|c|}
\hline \multirow{2}{*}{\multicolumn{2}{|c|}{ Variable }} & Control group & Study group & \multirow{2}{*}{$\mathrm{z}$} & \multirow{2}{*}{$\mathrm{p}^{\mathrm{a}}$} \\
\hline & & $\mathrm{X} \pm \mathrm{SD}$ & $\mathrm{X} \pm \mathrm{SD}$ & & \\
\hline \multicolumn{2}{|l|}{ Age (years) } & $24.83 \pm 0.88$ & $24.58 \pm 0.73$ & -0.145 & $0.887^{\mathrm{a}}$ \\
\hline \multicolumn{2}{|l|}{ Height (cm) } & $177.5 \pm 1.67$ & $176 \pm 1.77$ & -0.522 & $0.630^{\mathrm{a}}$ \\
\hline \multicolumn{2}{|l|}{ Weight (kg) } & $79.25 \pm 2.85$ & $75.91 \pm 2.51$ & -0.867 & $0.410^{\mathrm{a}}$ \\
\hline \multirow[t]{4}{*}{ Level of Education } & $\begin{array}{l}\text { No formal } \\
\text { education }\end{array}$ & $2(16.67 \%)$ & $1(8.33 \%)$ & & \multirow{4}{*}{$0.859^{b}$} \\
\hline & $\begin{array}{l}\text { Primary - middle } \\
\text { school }\end{array}$ & $4(33.3 \%)$ & $3(25 \%)$ & & \\
\hline & $\overline{\text { High school }}$ & $3(25 \%)$ & $4(33.3 \%)$ & & \\
\hline & University & $3(25 \%)$ & $4(33.3 \%)$ & & \\
\hline \multirow[t]{2}{*}{ Smoking status } & Smoker & $5(41.67 \%)$ & $4(33.3 \%)$ & & \multirow[b]{2}{*}{$0.219^{b}$} \\
\hline & Non-smoker & $7(58.33 \%)$ & $8(66.7 \%)$ & & \\
\hline \multirow[t]{2}{*}{ Dominant side } & Right & $9(75.5 \%)$ & $10(83.33 \%)$ & & \multirow[b]{2}{*}{$0.615^{b}$} \\
\hline & $\overline{\text { Left }}$ & $3(25 \%)$ & $2(16.67 \%)$ & & \\
\hline \multirow[t]{3}{*}{ Marital status } & Married & $6(50 \%)$ & $6(50 \%)$ & & \multirow[b]{3}{*}{$0.513^{\mathrm{b}}$} \\
\hline & $\overline{\text { Single }}$ & $2(16.67 \%)$ & $4(33.3 \%)$ & & \\
\hline & Divorced & $4(33.3 \%)$ & $2(16.67 \%)$ & & \\
\hline Spinal cord injury & T6 & $1(8.33 \%)$ & $2(16.67 \%)$ & & \multirow{7}{*}{-} \\
\hline \multirow[t]{6}{*}{ level } & $\mathrm{T} 7$ & $2(16.67 \%)$ & $1(8.33 \%)$ & & \\
\hline & $\mathrm{T} 8$ & $2(16.67 \%)$ & $2(16.67 \%)$ & & \\
\hline & $\overline{\mathrm{T} 9}$ & $2(16.67 \%)$ & $3(25 \%)$ & & \\
\hline & $\mathrm{T} 10$ & $2(16.67 \%)$ & $2(16.67 \%)$ & & \\
\hline & $\overline{\mathrm{T} 11}$ & $2(16.67 \%)$ & $1(8.33 \%)$ & & \\
\hline & $\overline{\mathrm{T} 12}$ & $1(8.33 \%)$ & $1(8.33 \%)$ & & \\
\hline
\end{tabular}

*p<0.05; X: Mean, SD: Standard Deviation; $\mathrm{p}^{\mathrm{a}}=$ Mann Whitney U test; $\mathrm{p}^{\mathrm{b}}=$ Chi-square Test 
The distribution of pain values in both groups is shown in Table 2. Pain in the neck and shoulders was determined in $>75 \%$ of the individuals using a wheelchair because of SCI.

Table 2. Pain distribution of the study subjects

\begin{tabular}{lccccc}
\hline & \multicolumn{2}{c}{ Control group $(\mathrm{n}=12)$} & Study group & $(\mathrm{n}=12)$ & \\
& $\mathrm{N}$ & $\%$ & $\mathrm{~N}$ & $\%$ & $\mathrm{p}$ \\
\hline Neck & 9 & 75 & 10 & 83.33 & 0.615 \\
\hline Shoulder & 9 & 75 & 9 & 75 & 1.000 \\
\hline Elbow & 6 & 50 & 4 & 33.33 & 0.408 \\
\hline Hand/ Wrist & 5 & 41.67 & 5 & 41.67 & 1.000 \\
\hline * $<<0.05 ;$ Chi-square test & & & & &
\end{tabular}

In the evaluations of the control and study groups, no significant difference was determined between the groups in respect of the pre-training head and shoulder posture values $(p>0.05)$. In the posture evaluations after the 4-week exercise training period, the shoulder posture value in the study group showed a significantly greater improvement than in the control group $(\mathrm{p}<0.05)$. The head and shoulder posture was determined to be better in the study group (Table 3 ).

Table 3. Comparisons of the pre and post-training head and shoulder values of the groups

\begin{tabular}{|c|c|c|c|c|c|}
\hline & & $\begin{array}{l}\text { Control Group } \\
(\mathrm{n}=12)\end{array}$ & $\begin{array}{c}\text { Study Group } \\
(\mathrm{n}=12)\end{array}$ & & \\
\hline & & $\mathrm{X} \pm \mathrm{SD}$ & $\mathrm{X} \pm \mathrm{SD}$ & $\mathrm{z}$ & $\mathrm{p}$ \\
\hline \multirow[t]{2}{*}{ Pre-training } & Head & $50.00 \pm 2.45$ & $51.08 \pm 2.78$ & 1.12 & 0.27 \\
\hline & Shoulder & $54.83 \pm 2.37$ & $54.58 \pm 2.23$ & 0.27 & 0.79 \\
\hline \multirow[t]{2}{*}{ Post-training } & Head & $50.42 \pm 2.71$ & $52.92 \pm 2.71$ & 2.09 & $0.04 *$ \\
\hline & Shoulder & $55.33 \pm 2.53$ & $57.92 \pm 2.68$ & 2.42 & $0.03 *$ \\
\hline
\end{tabular}

*p<0.05; X: Mean SD: Standard Deviation

In the comparisons of the pre and posttraining WUSPI, NDI, FSS, and FIM scores of the groups, all the scale values were seen to have significantly improved in the study group $(\mathrm{p}<0.05)$, and no significant improvement was determined in the control group $(\mathrm{p}>0.05)$ (Table 4).

Table 4. Comparison of the pre-training and post-training scores of the shoulder pain, neck disability, fatigue severity, and functional level scores of the groups

\begin{tabular}{llcccc}
\hline & Variables & \multicolumn{1}{c}{$\begin{array}{c}\text { Pre-training } \\
(\mathrm{n}=12)\end{array}$} & $\begin{array}{c}\text { Post-training } \\
(\mathrm{n}=12)\end{array}$ & $\mathrm{z}$ & $\mathrm{p}$ \\
\cline { 2 - 6 } Control group & WUSPI & $25.33 \pm 11.26$ & $24.88 \pm 10.96$ & 1.105 & 0.27 \\
\cline { 2 - 6 } & NDI & $0.39 \pm 0.16$ & $0.39 \pm 0.16$ & 0.00 & 1.00 \\
\cline { 2 - 6 } & FSS & $1.99 \pm 0.76$ & $1.98 \pm 0.81$ & 0.447 & 0.66 \\
\cline { 2 - 6 } Study group & FIM & $80.08 \pm 2.75$ & $80.08 \pm 2.75$ & 0.00 & 1.00 \\
\cline { 2 - 6 } & WUSPI & $23.25 \pm 10.59$ & $17.10 \pm 9.97$ & 3.062 & $0.002^{*}$ \\
\cline { 2 - 6 } & FDI & $0.45 \pm 0.15$ & $0.39 \pm 0.14$ & 2.950 & $0.003^{*}$ \\
\cline { 2 - 6 } & FSS & $1.87 \pm 0.72$ & $1.68 \pm 0.69$ & 2.831 & $0.01 *$ \\
\hline
\end{tabular}

*p<0.05; X: Mean, SD: Standard Deviation; WUSPI: Wheelchair Users Shoulder Pain Index; NDI: Neck Disability Index, FSS:

Fatigue Severity Scale, FIM: Functional Independence Measure 
In the comparison of the change in the values in the groups from pre to post-training, the difference was seen in the shoulder pain, neck problems, and fatigue values of the study group were found to be statistically significant $(\mathrm{p}<0.05)$.
A significant change was determined in the functional independence values of the study group after training, but no difference was found between the groups $(\mathrm{p}>0.05)$ (Table 5).

Table 5. Comparison of the differences in the pre-training and post-training scores of the shoulder pain, neck disability, fatigue severity, and functional level scores of the groups

\begin{tabular}{lcccc}
\hline & Control Group (n=12) & Study Group (n=12) & $\mathrm{t} / \mathrm{z}$ & $\mathrm{p}$ \\
\hline Variables & $\mathrm{X} \pm \mathrm{SD}$ & $\mathrm{X} \pm \mathrm{SD}$ & & \\
\hline WUSPI & $0.21 \pm 1.84$ & $6.15 \pm 2.75$ & -6.228 & $0.001^{* \mathrm{a}}$ \\
\hline NDI & $0.00 \pm 1.65$ & $0.63 \pm 1.78$ & -3.284 & $0.001^{* \mathrm{a}}$ \\
\hline FSS & $0.02 \pm 0.09$ & $0.20 \pm 0.13$ & -3.290 & $0.001^{* \mathrm{a}}$ \\
\hline FIM & $0.00 \pm 0.43$ & $0.42 \pm 0.51$ & -2.000 & $0.114^{\mathrm{b}}$
\end{tabular}

*p<0.05; $\mathrm{p}^{\mathrm{a}}$ : İndependent Sample test; $\mathrm{p}^{\mathrm{b}}$ : Mann-Whitney U test; X: Mean; SD: Standard Deviation; WUSPI: Wheelchair Users Shoulder Pain Index; NDI: Neck Disability Index; FSS: Fatigue Severity Scale; FIM: Functional Independence Measure

In the comparison of the differences in quality of life values of the groups' pre and posttraining, the psychological health $(\mathrm{p}=0.001)$, social relationships $(\mathrm{p}=0.004)$, and total scale points
( $p=0.001)$ were determined to be statistically significantly better in the study group. No difference was observed in the other scores ( $p>0.05)$ (Table 6).

Table 6. Comparison of the differences in the pre-training and post-training scores of the quality of life scores of the groups

\begin{tabular}{|c|c|c|c|c|}
\hline & $\begin{array}{l}\text { Control Group } \\
(\mathrm{n}=12)\end{array}$ & $\begin{array}{l}\text { Study Group } \\
\quad(\mathrm{n}=12)\end{array}$ & & \\
\hline \multicolumn{5}{|l|}{ Quality of Life } \\
\hline & $\mathrm{X} \pm \mathrm{SD}$ & $\mathrm{X} \pm \mathrm{SD}$ & $\mathrm{Z}$ & $\mathrm{p}$ \\
\hline General health & $1.04 \pm 3.60$ & $6.25 \pm 9.97$ & -1.739 & 0.082 \\
\hline Physical health & $0.59 \pm 2.56$ & $2.77 \pm 5.42$ & -1.119 & 0.263 \\
\hline Psychological health & $0.34 \pm 2.14$ & $6.59 \pm 4.84$ & -3.376 & $0.001 *$ \\
\hline Social relationships & $0.69 \pm 4.28$ & $7.63 \pm 6.60$ & -2.865 & $0.004 *$ \\
\hline Support network & $-0.34 \pm 1.92$ & $1.30 \pm 2.81$ & -1.798 & 0.072 \\
\hline Total measurement & $0.58 \pm 0.90$ & $3.00 \pm 0.95$ & -4.002 & $0.001 *$ \\
\hline
\end{tabular}

*p<0.05; X: Mean, SD: Standard Deviation

\section{DISCUSSION}

Two different therapeutic exercise programs were applied to those who used wheelchairs due to SCI in the Syrian War in the refugee camp. The hypothesis established at the beginning of the study was that the addition of scapula and trunk exercises to upper extremity exercises would have a greater effect on correcting head and neck posture, increasing functional capacity, and decreasing fatigue levels than the upper extremity strengthening program alone. The study results confirmed this hypothesis.

Harvey reported that different treatment approaches could be used in SCI. It was emphasized that applications used within many standard physiotherapy practices, such as active or passive normal joint movements, strengthening exercises, and breathing exercises, could be used in treatments following SCI (Harvey, 2016). 
Bayramlar, suggested encouraging sport after SCI and recommended various sports activities (Bayramlar, 2009). Previous studies have stressed the need for training on the point of exercises for wheelchair users. It has also been reported that wheelchair users need exercise intervention to achieve better health parameters (Günal et al., 2013).

In a systematic review by Hicks et al. to determine the efficacy of exercises in individuals using a wheelchair after SCI, it was reported that the efficacy of upper extremity exercises on body composition or postural correction could not be clearly seen (Hicks et al., 2011). The groups in the current study were homogenous in respect of clinical and demographic data, and this was thought to be useful in providing more cleare results in determining the effect of the training programs given between the groups. In the cases evaluated in the control group, no postural improvement was seen, whereas, in the study group, an increase was obtained in the head and shoulder angle values together with an improvement in head posture and shoulder protraction posture. Thus it can be said that the addition of the modified push-up, roller on the wall, and resistance band exercises targeted at the trunk and scapula muscles could be effective in the elimination of postural problems. Therefore, it can be considered beneficial to vary the exercises given to patients with SCI.

Being a wheelchair user with overloading and repeated overhead activities as a result of wheelchair use especially going up slopes and transfer on uneven surfaces, has been reported to cause often pain in the neck and shoulder regions and loss of function (Van Drongelen et al., 2005; Craig et al., 2012).

In literature, it has been emphasized that shoulder pain and quality of life affect each other in inverse proportion in individuals using a wheelchair after SCI (Gutierrez et al., 2007; Curtis et al., 1999). The shoulder joint is very mobile but is formed of structures vulnerable to injury, and disabled individuals using manual wheelchairs in particular, often use the head and neck, upper body and shoulder complex to compensate in functional activities. Therefore, stable and smooth working of these regions is of great importance to preserve the quality of life in these individuals. For the shoulder complex to function at the optimal level, there has to be smooth working in the form of a combination of the system including, the scapulohumeralthoracic region (Heyward et al., 2017; Mottram, 1997). Exercise programs including this region in respect of preserving range of movement and providing a stable environment when necessary will enable the individual to be more resistant to injuries that could occur. Accordingly, it can be thought that the addition of scapula and trunk exercises to upper extremity exercises will be effective in improving the quality of life of patients. These exercises will reduce pain and allow patients to be more independent in their daily living activities. In the pre and post-training measurements of the current study, while there was observed to be a significant improvement in the severity of shoulder pain in the study group, this was not seen in the control group. This demonstrated that upper extremity and scapular muscle strengthening exercises reduced shoulder pain, but strengthening exercises of the upper extremity muscles alone did not provide this effect. The functional independence levels showed a significant difference compared to the pretraining values, especially in the study group. The new additions of the trunk and scapula regions to the upper extremity exercise protocol for wheelchair users after SCI can be considered to have provided positive effects on the shoulder pain, functional levels, and in parallel to these, the quality of life of the patients.

In a previous randomized controlled study, the effect was investigated of the recommendation of an exercise program and movement optimization to optimize upper extremity movement performance in people with paraplegia with SCI. The exercise and movement optimization aimed for the application of 12-week home-based shoulder strengthening and stretching exercises and information about wheelchair use techniques for transfer and raising the weight. The control group watched a 1-hour training video. Improvements in shoulder pain, muscle strength, activity, and quality of life values were observed to be better in the study group (Mulroy et al., 2011). In another study, the recommendations are given for a 12-week exercise intervention and movement optimization resulted in a decrease in shoulder pain, and this was seen to be related to improved social participation and quality of life (Kemp et al., 2011). These results in the literature support the findings of the current study. The quality of life sub-categories of psychological health and social 
relationships and the total quality of life values were significantly more improved in the study group. Thus it can be said that the longer the time spent with the therapist in treatment will be effective as much as the decrease in pain and increase in functionality.

While some studies have suggested that complaints in the shoulder region have been ameliorated with exercise (Fullerton et al., 2003; Finley and Rodgers, 2004), others have reported an increase in complaints, especially fatigue. This could be attributed to overuse of the muscles in the training and muscular imbalance. Beyond this reason, it can be said that it is important to find a middle way in treatment and to apply training in such a way as to obtain maximum benefit by doing sufficient physical activity while preventing overuse of the muscles (Akbar et al., 2015; Yildirim et al., 2010). The findings of a study of 41 paraplegic subjects showed that exercises requiring eccentric muscle contractions resulted in less muscle fatigue than exercises requiring concentric muscle contractions, and these results contribute to the current study (Mayer et al., 2000). In the current study, although the study group performed additional exercises, the fact that the fatigue levels were lower demonstrates that the inclusion of large muscles in training and that some of the prescribed exercises were eccentric exercises contributed to the lower level of fatigue by the distribution of the forces. In another study, impairment of the normal work/rest cycle of the muscles was said to increase localized muscle fatigue and the risk of pain (Middaugh et al., 2013). When it is considered that the activities of wheelchair users are repeated as well as leading to overuse, it can be said that different exercises to be performed other than repeated movements and those increasing muscle endurance will contribute to the normal cycle of the muscle. Therefore, to increase resistance to the stresses which could form in the body, the exercise program selected is essential. This can play a preventative role against both cumulative injuries and secondary effects, which can occur as a result of these.

It has been emphasized in a previous study that exercise develops both mental and physical performance. However, it has also been reported that motivation is important for the performance and maintenance of exercises. The importance of starting exercises under supervision, supervised maintenance and subsequent follow-up has also been stated (Knapen et al., 2015). Therefore, to maintain the motivation of these wheelchair-bound patients who have experienced physical loss, it is important that the exercises are performed under the guidance of a therapist and that there is continued follow-up. This will reduce problems due to incorrect performance of the exercises and enable the patients to gain the ability to continue the exercises and thereby contribute to the improvement of health parameters.

There were some limitations to this study, primarily that the training and follow-periods were short as it depended on the time that the refugees stayed in the camp. In addition, taking refugee and patient psychology into consideration, the accuracy of the responses of the participants could not be proven, which could be considered another limitation. Valuation of the problems of wheelchair users with a holistic view is significant. Patients with SCI are a heterogenous group related to the differences in lesion level and comorbidities, so prevalences are low. This creates a barrier to collecting the large, homogenous samples needed for scientific research. Nevertheless, this study can be considered a reference in the establishment of evidence of the benefits and effects of exercise for SCI patients.

In conclusion, this study's results demonstrated that a 4-week therapeutic exercise program applied to individuals using a wheelchair because of SCI sustained in war had a significant positive effect on head and shoulder posture, shoulder pain, functional capacity, neck disability, and quality of life levels.

There is a need for studies to reduce pain and fatigue, increase muscle strength, functionality, and quality of life with exercise programs in individuals with disabilities who use wheelchair after SCI. Besides, it is crucial to evaluate and treat disabled patients who are victims of war in a multidisciplinary environment, help individuals adapt to social life, direct them to sports, encourage them, and reintegrate individuals with disabilities into society by increasing the opportunities to do sports.

\section{Conflict of interests:}

The authors have no conflict of interests to declare. No financial support was received for this study. 
REFERENCES

Ahmadi, A., Maroufi, N., \& Sarrafzadeh, J. (2016). Evaluation of forward head posture in sitting and standing positions. Eur Spine $J$, 25(11),3577-3582.doi.org/10.1007/s00586015-4254-X

Akbar, M., Brunner, M., Ewerbeck, V., Wiedenhöfer, B., Grieser, T., Bruckner, T., et al. (2015). Do Overhead Sports Increase Risk for Rotator Cuff Tears in Wheelchair Users? Arch Phys Med Rehabil, 96, 484488.

https://doi.org/10.1016/j.apmr.2014.09.032

Armutlu, K., Korkmaz, N. C., Keser, I., Sumbuloglu, V., Akbiyik, D.I., Guney, Z., \& Karabudak, R. (2007). The Validity and Reliability of The Fatigue Severity Scale in Turkish Multiple Sclerosis Patients. Int J Rehabil Res, 30(1), 81-85.

doi:10.1097/MRR.0b013e3280146e4

Aslan, E., Karaduman, A., Yakut, Y., Aras, B., Simsek, I. E., \& Yaglý, N. (2008). The Cultural Adaptation, Reliability and Validity of Neck Disability Index in Patients With Neck Pain: A Turkish Version Study. Spine, 33(11),E362-5.doi:10.1097/BRS.0b013e318 $17144 \mathrm{e} 1$

Bayramlar, K. (2009). Recreational Activities and Sports for Orthopedic Disabled People. Ankara Journal of Health Services, 8(1), 2327.

Buchholz, A.C., McGillivray, C.F., \& Pencharz, P.B. (2003). Physical Activity Levels are Low in Free-Living Adults with Chronic Paraplegia. Obesity Res, 11(4), 563-570. https://doi.org/10.1038/oby.2003.79

Craig, A.,Tran, Y., Wijesuriya, N., \& Middleton, J. (2012). Fatigue and Tiredness in People With Spinal Cord Injury. J Psychosom Res, 73(3),205-210.doi.org/10.1016/j.jpsychores. 2012.07.005

Curtis, K.A., Drysdale, G.A., Lanza, R.D., Kolber, M., Vitolo, R.S., et al. (1999). Shoulder Pain in Wheelchair Users with Tetraplegia and Paraplegia. Arch Phys Med Rehabil, 80(4), 453-457.doi.org/10.1016/S00039993(99)902 $85-\mathrm{X}$

Curtis, K.A., Roach, K.E., Applegate, E.B., Amar, T., Benbow, C.S., Genecco, T.D., \& Gualano, J. (1995). Development of the Wheelchair User's Shoulder Pain Index
(WUSPI). Spinal Cord, 33(5), 290-293. https://doi.org/10.1038/sc.1995.65

Curtis, K.A., Tyner T.M., Zachary, L., Lentell, G., Brink, D., et al. (1999). Effect of a Standard Exercise Protocol on Shoulder Pain in LongTerm Wheelchair Users. Spinal Cord, 37(6), 421. https://doi.org/10.1038/sj.sc.3100860

Eser, E., Fidaner, H., Fidaner, C., Eser, S.Y., Elbi, H., \& Göker, E. (1999). Psychometric properties of tlte WHOQOL-100 and WHOOOLBREF. Psikiyatri Psikoloji Psikofarmakoloji Dergisi, 7(Suppl 2), 23-40.

Finley, M.A., Rodgers, M. M. (2004). Prevalence and Identification of Shoulder Pathology in Athletic and Nonathletic Wheelchair Users with Shoulder Pain: A Pilot Study. J Rehabil Res Dev, 41, 395-402. doi: 10.1682/jrrd. 2003.02.0022

Fullerton, H.D., Borckardt, J.J., \& Alfano, A.P. (2003). Shoulder Pain: A Comparison of Wheelchair Athletes and Nonathletic Wheelchair Users. Med Sci Sports Exerc, 35, 1958-1961.doi:10.1249/01.MSS.000009908 2.54522 .55

Gutierrez, D.D., Thompson, L., Kemp, B., \& Mulroy, S.J. (2007). The Relationship of Shoulder Pain Intensity to Quality of Life, Physical Activity, and Community Participation in Persons with Paraplegia. $J$ Spinal Cord Med, 30(3), 251-255. https://doi.org/10.1080/10790268.2007.1175 3933

Günal, A., Uyanık, M., Başkurt, F., Başkurt, Z., \& Parpucu, T. İ. (2013). Exercise Awareness and Lifestyle in Wheelchair Users: Pilot Study. Journal of Occupational Therapy and Rehabilitation, 1(2), 141-142.

Hall, K., Hamilton, B., Gordon, W., \& Zasler, N. (1993). Characteristics and Comparisons of Functional Assessment Indices. J Head Trauma Rehabil, 8(2), 60-74. doi.org/10.1097/00001199-199308020 00008

Heyward, O.W., Vegter, R., de Groot, S., \& van der Woude, L. (2017). Shoulder Complaints in Wheelchair Athletes: A Systematic Review. PloS one, 12(11),e0188410. doi.org/10.1371/journal.pone.0188410

Harvey L.A. (2016). Physiotherapy Rehabilitation for People with Spinal Cord Injuries. $J$ Physiother,62(1),411.doi.org/10.1016/j.jphys .2015 .11 .004 
Hicks, A.L., Ginis, K.M., Pelletier, C.A., Ditor, D.S., Foulon, B., et al. (2011). The Effects of Exercise Training on Physical Capacity, Strength, Body Composition and Functional Performance Among Adults with Spinal Cord Injury: A Systematic Review. Spinal Cord,49(11),1103.

https://doi.org/10.1038/sc.2011.62

Hicks, A., Martin, K., Ditor, D. et al. (2003). Long-Term Exercise Training in Persons with Spinal Cord Injury: Effects on Strength, Arm Ergometry Performance and Psychological Well-Being. Spinal Cord,41,34-43.doi.org/10.1038/sj.sc.310138 9

Kemp, B.J., Bateham, A.L., Mulroy, S.J., Thompson, L., Adkins, R.H., \& Kahan, J.S. (2011). Effects of Reduction in Shoulder Pain on Quality of Life and Community Activities Among People Living Long-Term with SCI Paraplegia: A Randomized Control Trial. J Spinal Cord Med, 34(3), 278-284. https://doi.org/10.1179/107902611X129724 48729486

Kirby, R.L., de Groot, S., \& Cowan, R.E. (2020). Relationship Between Wheelchair Skills Scores and Peak Aerobic Exercise Capacity of Manual Wheelchair Users with Spinal Cord Injury: A Cross-Sectional Study. Disabil Rehabil, 42(1), 114-121. https://doi.org/10.1080/09638288.2018.1493 545

Knapen, J., Vancampfort, D., Moriën, Y., \& Marchal, Y. (2015). Exercise Therapy Improves Both Mental and Physical Health in Patients with Major Disabil Rehabil, 37(16),1490-1495.doi.org/10.3109/09638288 .2014 .972579

Kressler, J., Cowan, R.E., Bigford, G.E., \& Nash, M.S. (2014). Reducing Cardiometabolic Disease in Spinal Cord Injury. Phys Med Rehabil Clin N Am, 25(3), 573-604. https://doi.org/10.1016/j.pmr.2014.04.006

Küçükdeveci, A.A., Yavuzer, G., Elhan, A.H., Sonel, B., \& Tennant, A. (2001). Adaptation of the Functional Independence Measure for Use in Turkey. Clin Rehabil, 15(3), 311-319. https://doi.org/10.1191/02692150167687726 5

Mayer, F., Horstmann, T., Röcker, K., Niess, A., Bäurle, W., et al. (2000). Concentric and Eccentric Shoulder Muscle Fatique in
Dependence on Exertion in Sportsand Daily Living. Medicine \& Science in Sports \& Exercise, (32), 5.

Middaugh, S., Thomas, K.J., Smith, A.R., McFall, T.L., \& Klingmueller, J. (2013). EMG Biofeedback and Exercise for Treatment of Cervical and Shoulder Pain in Individuals with a Spinal Cord Injury: A Pilot Study. Top Spinal Cord Inj Rehabil, 19(4), 311323. https://doi.org/10.1310/sci1904-311

Mottram, S. (1997). Dynamic Stability of the Scapula. Man Ther, 2, 123-31. doi.org/10.1054/math. 1997.0292

Mulroy, S J., Thompson, L., Kemp, B., Hatchett, P.P., Newsam, C.J., Lupold, D.G., et al. (2011). Strengthening and Optimal Movements for Painful Shoulders (STOMPS) in Chronic Spinal Cord İnjury: A Randomized Controlled Trial. Phys Ther, 91(3),305-324.doi.org/10.2522/ptj.20100182

Nichols, P.J., Norman, P.A., \& Ennis, J.R. (1979). Wheelchair User's Shoulder? Shoulder Pain in Patients with Spinal Cord Lesions. Scand J Rehabil Med, 11(1), 29-32.

Rose, M., Robinson, J.E., Ells, P., \& Cole, J.D. (1988). Pain Following Spinal Cord Injury: Result From a Postal Survey. Pain, 34(1), 101-102. doi: 10.1016/0304-3959(88)90187$\mathrm{X}$

Ruivo, R.M., Pezarat-Correia, P., \& Carita, A.I. (2017). Effects of a Resistance and Stretching Training Program on Forward Head and Protracted Shoulder Posture in Adolescents. J Manipulative Physiol Ther, 40(1),1-10.doi.org/10.1016/j.jmpt.2016.10.0 05

Sakai, M., Mutsuzaki, T., Shimizu, Y., Okamoto, Y., Yatabe, K., Muraki, I., \& Nakajima, K. (2020). Characteristic MRI Findings of Shoulder, Elbow, and Wrist Joints in Wheelchair User. Skeletal Radiol, 1-8. https://doi.org/10.1007/s00256-020-03545-2

Subbarao, J. V., Klopfstein, J., \& Turpin, R. (1995). Prevalence and Impact of Wrist and Shoulder Pain in Patients with Spinal Cord Injury. J Spinal Cord Med, 18(1), 9-13. https://doi.org/10.1080/10790268.1995.1171 9374

Tatlı, M., Güzel, A., Ökten, A.İ., \& Çaylı, S. (2005). Medical Management of Spinal Cord İnjuries. Cukurova Medical Jourmal, 27 (4), $165-172$. 
Tolerico, M.L., Ding, D., Cooper, R.A., Spaeth, D.M., Fitzgerald, S.G., Cooper, R., et al. (2007). Assessing Mobility Characteristics and Activity Levels of Manual Wheelchair Users. J Rehabil Res Dev, 44, 561.

Van Drongelen, S., Van der Woude, L.H., Janssen, T.W., Angenot, E.L., Chadwick, E.K., et al. (2005). Mechanical Load on the Upper Extremity During Wheelchair Activities. Arch Phys Med Rehabil, 86(6),1214-1220. https://doi.org/10.1016/j.apmr.2004.09.023

Vernon, H., \& Mior, S. (1991). The Neck Disability Index: A Study of Reliability and Validity. J Manipulative Physiol Ther, 14, 409-415.

Yildirim, N.U., Comert, E., \& Ozengin, N. (2010). Shoulder Pain: A Comparison of Wheelchair Basketball Players with Trunk Control and Without Trunk Control. Back Musculoskelel Rehabil, 23, 55-61. doi:10.3233/BMR-20100250

Yilmaz Ş. (2017). Turkish Adaptation of Wheelchair User's Shoulder Pain Index: Validity and Reliability Study. Master's Thesis, Gazi University, Health Sciences Institute, Ankara.

WHO-QoL Group. (1998). Development of the World Health Organization Whoqol-BREF Quality of Life Assessment. Psychol Med, 28(3),551-558.doi.org/10.1017/s0033291798 006667

How to cite this article: Hassan, A., Y1lmaz, R.C. and Tuncer, A., (2021). The Effect of Exercise Training for Refugee Wheelchair Users. Int J Disabil Sports Health Sci;4(1):6172. https://doi.org/10.33438/ijdshs. 874253 